\title{
Implementasi Kebijakan Program Lesson Study Berbasis Sekolah (LSBS) di MINU Trate Putri Gresik
}

\author{
Suyanik*, Erny Roesminingsih \\ Jurusan Manajemen Pendidikan, Universitas Negeri Surabaya \\ *Corresponding Author. Email: suyanik.19017@mhs.unesa.ac.id
}

\begin{abstract}
This research aims to describe the course of policy implementation Lesson Study, to know the things that support and are an obstacle in implementing policies and programs Lesson Study to determine the impact / results in implementing the policy program at the Lesson study MINU Trate Putri Gresik. This research uses Qualitative approaches, data collection technique through the process of observation, interviews, documentation, and questionnaires. Data analysis was performed based on four interrelated components, namely data collection, data reduction, presentation of data, the data inference. For overcome the obstacles that occur MINU Trate Putri always try to maximize all of the potential that exists. Among them is the rescheduling of any activity that is not done, the conversion or exchange of teaching hours to be optimal in the observation, as well as the fulfillment of all the necessary infrastructure. The impact of the implementation of the School-Based Lesson Study program includes a change in the paradigm of teachers in a more open, creative and collaborative learning process as well as increasing achievements that have been achieved by students, teachers and schools in general.
\end{abstract}

\begin{abstract}
Abstrak: Penelitian ini bertujuan untuk mendeskripsikan implementasi kebijakan program Lesson Study, hal-hal yang menunjang dan yang menjadi kendala dalam mengimplementasikan kebijakan program Lesson Study, solusi pemecahan atas kendala yang dihadapi dan untuk mengetahui dampak/hasil dalam mengimplementasikan kebijakan program Lesson Study di MINU Trate Putri Gresik. Penelitian ini menggunakan pendekatan kualitaif, teknik pengumpulan data melalui proses observasi, wawancara, dokumentasi, dan kuesioner. Analisis data dilakukan berdasarkan empat komponen yang saling berkaitan yaitu pengumpulan data, reduksi data, pemaparan data, penyimpulan data. Kesimpulan yang diperoleh dari hasil penelitian yang dilakukan dalam pengimplementasian kebijakan program Lesson Study yaitu semua kegiatan dilakukan sesuai dengan kriteria dari Kementerian Pendidikan. Dampak dari implementasi program Lesson Study Berbasis Sekolah ini meliputi adanya perubahan paradigma para guru dalam proses pembelajaran yang lebih terbuka, kreatif dan kolaboratif serta semakin bertambahnya prestasi yang telah diraih oleh siswa, guru maupun sekolah secara umum.
\end{abstract}

Article History

Received: 05-04-2021

Revised: 11-05-2021

Accepted: 20-05-2021

Published: 07-07-2021

\section{Key Words:}

Implementation,

Policy, Lesson

Study.

\section{Sejarah Artikel}

Diterima: 05-04-2021

Direvisi: 11-05-2021

Disetujui: 20-05-2021

Diterbitkan: 07-07-2021

\section{Kata Kunci:}

Implementasi, Kebijakan, Lesson Study.

How to Cite: Suyanik, S., \& Roesminingsih, E. (2021). Implementasi Kebijakan Program Lesson Study Berbasis Sekolah (LSBS) di MINU Trate Putri Gresik. Jurnal Paedagogy, 8(3), 296-303. doi:https://doi.org/10.33394/jp.v8i3.3692

d.

https://doi.org/10.33394/jp.v8i3.3692

This is an open-access article under the CC-BY-SA License.

\section{Pendahuluan}

Peraturan Pemerintah Nomer 19 Tahun 2005, Pasal 19, ayat 1 menyatakan bahwa proses pembelajaran pada satuan pendidikan diselenggarakan secara interaktif, inspiratif, menyenangkan, menantang, memotivasi peserta didik untuk berpartisipasi aktif, serta memberikan ruang yang cukup bagi prakarsa, kreativitas, sesuai dengan bakat, minat, dan perkembangan fisik serta psikologis peserta didik. Dalam Undang-undang Guru dan Dosen disebutkan bahwa seorang guru harus memiliki kompetensi pedagogik, kompetensi 
profesional, kompetensi kepribadian, dan kompetensi sosial. Dalam kompetensi pedagogik dan profesional, guru diharapkan mampu mengkaji di setiap pembelajarannya agar pembelajaran yang dilakukan lebih bermakna.

Alasan menggunakan lesson study, pertama, lesson study merupakan suatu cara efektif yang dapat meningkatkan kualitas mengajar guru dan aktivitas belajar peserta didik. Hal ini benar, karena (1) pengembangan lesson study dilakukan dan didasarkan pada hasil "sharing" pengetahuan profesional yang berlandaskan pada praktek dan hasil pengajaran yang dilaksanakan para guru, (2) penekanan mendasar suatu lesson study adalah para peserta didik memiliki kualitas belajar, (3) tujuan pelajaran dijadikan fokus dan titik perhatian utama dalam pembelajaran di kelas, (4) berdasarkan pengalaman real di kelas, lesson study mampu menjadi landasan bagi pengembangan pembelajaran, dan (5) lesson study akan menempatkan peran para guru sebagai peneliti pembelajaran (Lewis, 2002).

Alasan yang kedua, lesson study yang didesain dengan baik akan menghasilkan guru yang profesional dan inovatif. Dengan melaksanakan lesson study para guru dapat (1) menentukan tujuan, pelajaran (lesson), satuan (unit) pelajaran, dan mata pelajaran yang efektif; (2) mengkaji dan meningkatkan pelajaran yang bermanfaat bagi peserta didik; (3) memperdalam pengetahuan tentang mata pelajaran yang disajikan para guru; (4) menentukan tujuan jangka panjang yang akan dicapai para peserta didik; (5) merencanakan pelajaran secara kolaboratif; (6) mengkaji secara teliti belajar dan perilaku peserta didik; (7) mengembangkan pengetahuan pembelajaran yang dapat diandalkan; dan (8) melakukan refleksi terhadap pengajaran yang dilaksanakannya berdasarkan pandangan peserta didik dan koleganya (Lewis, 2002)

Inerson dan Yoshida (2005) mengatakan bahwa lesson study memiliki beberapa manfaat sebagai berikut: mengurangi keterasingan guru (dari komunitasnya), membantu guru untuk mengobservasi dan mengkritisi pempelajarannya, memperdalam pemahaman guru tentang materi pelajaran, cakupan dan urutan kurikulum, membantu guru memfokuskan bantuannya pada seluruh aktivitas belajar peserta didik. Menciptakan terjadinya pertukaran harapan-harapan untuk pemahaman berpikir dan belajar peserta didik, meningkatkan kolaborasi perhatian pada sesama guru.

Secara normatif, program ini didasarkan kepada kebutuhan akan pendekatan pengembangan profesional yang holistik, terintegrasi dan berkelanjutan dalam rangka menunjang implementasi dari UU No. 20/2003 tentang Sistem Pendidikan Nasional, PP No. 19/2005 tentang Standar Nasional Pendidikan dan UU No. 14/2005 tentang Guru dan Dosen. Peraturan tersebut menekankan pada peningkatan mutu pengajaran dan pembelajaran, peningkatan kompetensi dan profesionalitas guru serta dosen. Lewis A. Gunn mengemukakan sejumlah tahap implementasi meliputi penetapan rencana suatu program dan tujuan,dan dana kemudian struktur staf dan rumusan kegiatan penentuan jadwal, pemantauan, pengawasan. Konsep implementasi kebijakan program LSBS di MINU Trate Putri Gresik sangat ditentukan oleh rencana suatu program, tujuan, dana, struktur staf dan rumusan kegiatan .

Berdasar pada model implementasi tersebut, maka dalam penelitian ini akan dikaji tentang bagaimanakah implementasi kebijakan Program Lesson Study Berbasis Sekolah (LSBS) di MINU Trate Putri Gresik, faktor yang menunjang dan kendala-kendala apa saja yang dihadapi dalam proses pengimplementasian Program Lesson Study Berbasis Sekolah (LSBS) serta dampak/hasil implementasi kebijakan Program Lesson Study Berbasis Sekolah (LSBS) di MINU Trate Putri Gresik.

Konsep implementasi yang didefinisikan oleh Mazmanian-Sabatier dalam Wahab (1985) memberikan tekanan pada sisi proses, hasil dan dampak kebijakan. Definisi konsep 
tersebut adalah dalam mempelajari masalah implementasi kebijakan yang berarti berusaha untuk memahami apa yang senyatanya terjadi setelah suatu program diberlakukan atau dirumuskan, yakni peristiwa-peristiwa dan kegiatan-kegiatan yang terjadi setelah proses pengesahan kebijakan negara, baik itu menyangkut usaha-usaha untuk mengadministrasikannya maupun juga usaha-usaha untuk memberikan dampak tertentu pada masyarakat atau peristiwa-peristiwa.

Model implementasi dari Marilee S. Grindle pada artikel "Policy Contentand Context in Implementasi". Grindle berpendapat bahwa implementasi merupakan proses pengambilan keputusan tanpa henti oleh orang-orang yang terkait, yang merupakan hasil akhir yang ditentukan dari isi program yang dianut oleh hubungan pembuat keputusan dalam lingkup politik administratif. Kebijakan sebagai suatu taktik dan strategi yang diarahkan untuk mencapai satu tujuan, oleh karena kebijakan memuat tiga elemen antara lain adalah identifikasi dari suatu tujuan yang ingin dicapai, taktik dan strategi dari berbagai langkah untuk mencapai tujuan yang diinginkan, penyediaan berbagai input untuk memungkinkan pelaksanaan secara nyata dari taktik dan strategi (Amara, 2010)

Lesson study yang di dalam bahasa Jepang disebut jugyokenkyu adalah bentuk kegiatan yang di lakukan oleh guru / sekelompok guru yang bekerjasama dengan orang lain (dosen, guru mata pelajaran yang sama, guru satu tingkat kelas yang sama, atau guru lainnya) merancang kegiatan untuk meningkatkan mutu belajar siswa dari pembelajaran yang dilakukan oleh salah seorang guru dari perencanaan pembelajaran yang dirancang bersama/sendiri, kemudian diobservasi oleh teman guru yang lain dan setelah itu mereka melakukan refleksi bersama atas hasil pengamatan pembelajaran yang baru saja dilakukan. Refleksi bersama merupakan diskusi oleh para pengamat dan guru pengajar untuk menyempurnakan proses pembelajaran di mana titik berat pembahasan pada bagaimana siswa belajar, kapan siswa belajar, kapan siswa mulai bosan, kapan siswa mendapatkan pengetahuanya dan kapan siswa mampu menjelaskan kepada temannya dan kapan siswa mampu mengajarkan kepada seluruh kelas. Lesson Study Berbasis Sekolah (LSBS) adalah kegiatan lesson study yang dilaksanakan oleh beberapa atau semua guru yang berada dalam satu lingkungan sekolah. Sekolah yang dimaksud di sini adalah MINU Trate Putri Gresik. Secara umum bahwa kebijakan adalah serangkaian tindakan yang mempunyai tujuan tertentu diikuti dan dilaksanakan oleh seorang pelaku atau kelompok pelaku guna memecahkan masalah tertentu. Untuk keberhasilan pelaksanaan suatu kebijakan, tidak hanya kebijakan dirumuskan dengan baik tetapi juga memerlukan cara dan teknik tertentu serta dukungan, baik dari pihak perumus maupun pelaksana kebijakan.

Adapun tujuan penelitian ini adalah untuk mendeskripsikan implementasi kebijakan program Lesson Study, hal-hal yang menunjang dan yang menjadi kendala dalam mengimplementasikan kebijakan program Lesson Study, solusi pemecahan atas kendala yang dihadapi dan untuk mengetahui dampak/hasil dalam mengimplementasikan kebijakan program Lesson Study di MINU Trate Putri Gresik.

\section{Metode Penelitian}

Jenis penelitian ini adalah penelitian lapangan (field research) dengan menggunakan pendekatan kualitatif. Sedangkan metode penyajian data penelitian ini adalah metode deskriptif-analitik-evaluatif. Objek utama penelitian ini adalah Implementasi Kebijakan Lesson Study Berbasis Sekolah di SD Negeri Pranti kecamatan Menganti Gresik. Yang menjadi fokus penelitian adalah para guru dan juga siswa sebagai imbas dari kebijakan ini. Definisi data adalah bahan-bahan kasar (mentah) yang dikumpulkan oleh peneliti dari 
lapangan bisa berupa kata-kata, tindakan atau perilaku maupun sumser-sumber tertulis semisal dokumen, biografi, dan lain sebaginya. Sedangkan definisi sumber data adalah subyek dari data itu sendiri. Misalnya: apabila peneliti menggunakan teknik wawancara, maka sumber data disebut responden, yaitu orang yang menjawab pertanyaan-pertanyaan peneliti. Sumber data penelitian ini ada dua jenis,yaitu: a) sumber primer meliputi kepala sekolah, guru dan murid di SD Negeri Pranti kecamatan Menganti; b) sumber sekunder meliputi literatur-literatur yang terkait LSBS, baik berupa buku-buku maupun karya-karya ilmiah berupa skripsi, tesis, disertasi hingga jurnal. Tentu saja, sumber data dari internet juga sesekali dilibatkan demi meraih hasil penelitian yang lebih valid dan komprehensif. Teknik pengumpulan data dalam penelitian ini menggunakan teknik wawancara (interview), observasi, dokumentasi dan kuesioner.

Untuk memperoleh data-data yang terkait dengan penelitian ini, diperlukan adanya alat (instrumen). Sedangkan dalam penelitian kualitatif, manusia menjadi instrumen dari penelitian. Oleh sebab itu, posisi peneliti dalam penelitian kualitatif terbilang sangat rumit, karena dia memiliki banyak peran, misalnya perencana, pelaksana dan pengumpul data, penganalisis dan penafsiran data hingga pada akhirnya menjadi pelapor hasil penelitiannya. Peran-peran yang diajukan oleh Moleong (2014) ini akan peneliti jalani semaksimal mungkin.

Pemeriksaan terhadap keabsahan data, didasarkan atas sejumlah kriteria tertentu. Ada empat kriteria yang digunakan, yaitu derajat kepercayaan (credibility), keteralihan (transferability), kebergantungan (dependability), dan kepastian (confirmability). Untuk menguji keabsahan data yang diperoleh, peneliti menggunakan teknik triangulasi (cross check). Menurut Moleong, triangulasi adalah teknik pemeriksaan keabsahan data dengan memanfaatkan sesuatu yang lain di luar data itu untuk keperluan pengecekan atau sebagai pembanding terhadap data yang diperoleh. Teknik triangulasi yang digunakan adalah pemeriksaan melalui sumber lain. Teknik triangulasi dalam penelitian ini dilakukan dengan cara: membandingkan data hasil wawancara, observasi, dokumentasi dan kuesioner untuk kemudian ditampilkan dalam paparan data dan analisis data.

Selain teknik triangulasi, peneliti juga akan menggunakan teknik konsultasi dengan para ahli.. Teknik ini dilakukan untuk memperoleh saran, kritik, dan masukan dari mereka untuk memperbaiki data-data hasil penelitian ini. Sedangkan untuk menguji validitas data, peneliti akan mencocokkan dan membandingkan data dari berbagai sumber, baik sumber data primer maupun sumber data sekunder. Analisis data adalah proses mengorganisasikan dan mengurutkan data ke dalam pola, kategori, dan satuan uraian dasar sehingga dapat ditemukan tema dan dapat dirumuskan hipotesis kerja seperti yang disarankan oleh data. Dalam penelitian ini, peneliti memakai teknik analisis isi (content analysis). Sedangkan sifat analisis datanya meliputi analisis naratif kualitatif, yaitu mencari kesamaan-kesamaan dan perbedaanperbedaan informasi, untuk menemukan hal-hal mendasar yang perlu dipaparkan dalam laporan penelitian ini secara komprehensif. Analisis naratif kualitatif sekaligus besifat komparatif, mengingat penelitian ini dilaksanakan di multi-situs, maka konsekuensinya, data yang diperoleh akan dianalisis secara komparatif. Lebih dari itu, teknik analisis data dalam penelitian ini juga bersifat analitik-sintesis dan evaluatif-kritis.

\section{Hasil Penelitian dan Pembahasan}

Dalam implementasi kebijakan program LSBS di MINU Trate Putri Gresik ada beberapa yang sesuai dengan model implementasi dari Lewis A. Gunn: a) Kebijakan Sekolah Model LSBS. Berkenaan dengan kebijakan sekolah model LSBS di MINU Trate Putri 
Gresik ini agar terjalin suatu koordinasi yang bagus dalam implementasi kebijakan program LSBS maka dalam kesempatan ini disampaikan beberapa hasil wawancara dan hasil kuesioner . Dari jawaban responden tersebut dapat disimpulkan bahwa memang benar ada empat indikator dalam pelaksanaan program LSBS yaitu adalah pengembangan kebijakan sekolah berbasis kolaboratif, pengembangan kurikulum berbasis LSBS, pengembangan pembelajaran berbasis lesson study, pengembangan dan atau pengelolaan sarana prasarana pendukung Pengembangan Kurikulum Berbasis Lesson Study. MINU Trate Putri Gresik dalam pengembangan kurikulumnya yang berbudaya, berwawasan lingkungan, berkeunggulan lokal, berpengetahuan global dan berbasis Lesson Study. 1). Membentuk Kelompok Lesson Study ,2) Memfokuskan Kegiatan Lesson Study 3) Merencanakan Research Lesson (RL) 4) Membelajarkan dan Mengamati Research Lesson (RL) Mendiskusikan dan Menganalisis Reseach Lesson (RL) Merefleksikan dan Merencanakan Kembali LSc. Pengembangan dan atau pengelolaan sarana pendukung sekolah Berbasis Lesson Study. Pengembangan dan pengelolaan sarana pendukung sekolah yang memadai sangat besar artinya dalam menunjang keberhasilan implementasi kebijakan program LSBS .

Langkah kebijakan program LSBS di MINU Trate Putri Gresik ini merupakan informasi dan komunikasi bersama yang dilakukan oleh kepala sekolah dengan seluruh warga sekolah untuk memperoleh komitmen bersama. Setelah kesepakatan bersama tersebut, kemudian dilakukan sosialisasi betapa pentingnya LSBS ini bagi sekolah agar tercapai sekolah yang peduli dan berbudaya lingkungan. Sosialisasi ini dilakukan melalui rapat dengan guru, tata usaha, orang tua siswa dan komite sekolah. Untuk warga sekolah tahap sosialisasi ini dilakukan melalui pertemuan dengan semua civitas akademika, baik guru, tenaga TU, karyawan, penjaga sekolah, siswa dan juga orang tua. Sosialisasi ini tentang program LSBS ini dilakukan secara terus menerus oleh sekolah dan tidak pernah putus asa untuk memompa semangat seluruh warga untuk meraih predikat sekolah nodel LSBS.

Kebijakan program LSBS ini memerlukan struktur dan tata kerja yang jelas, maka dibentuklah tim yang bertanggung jawab khusus menangani tentang program LSBS. Kepala sekolah sebagai pemimpin tertinggi di sekolah dibantu oleh staf guru, tata usaha dan siswa menciptakan sekolah yang berbasis lesson study. Dalam implementasi kebijakan program LSBS ini juga tidak lepas dari tersedianya sumber daya yang telah dimiliki oleh sekolah antara lain sarana prasarana, SDM terutama tenaga pengajar yang relatif berusia muda, jumlah siswa, partisipasi wali murid, dan masalah pendanaan.

Seiring dengan perkembangan pendidikan serta proses pembelajaran dengan memanfaatkan sarana terintegrasi TI untuk mewujudkan prestasi akademik dan non akademik, proses pembelajaran di kelas dari tahun ke tahun selalu mengalami perkembangan, selain disajikan secara perorangan, disajikan juga dalam bentuk integrasi, dan dalam kelompok MGMPS atau kelompok LS. Proses pembelajaran yang berjalan selama ini di SD Negeri Pranti Kecamatan Menganti sudah bervariasi. Pembelajaran sudah banyak yang berbasis PAIKEM bahkan PAIKEM GEMBROT. Dalam kelompok Lesson Study pembelajaran lebih bervariasi lagi. Suasana di kelas juga semakin hidup. Para siswa lebih aktif dan kreatif ketika pembelajarannya dilakukan dengan LS. Imbasnya banyak prestasi yang terukir sebagaimana yang tertuang di atas.

Hasil paparan di atas menggambarkan bahwa SD Negeri Pranti Kecamatan Menganti ingin memberikan sumbangsih pada warga sekolah, masyarakat, dinas pendidikan di lingkungan Kabupaten Gresik, serta seluruh elemen masyarakat, agar lebih mengembangkan proses pendidikan yang lebih memanusiakan anak didik, mengedepankan aspek kerja sama dan mawas diri. 
Pada tahun 2010 Dinas Pendidikan Kabupaten Gresik meluncurkan program sekolah model. Sekolah Model adalah Sekolah berstandar SKM (Sekolah Kategori Mandiri) yang telah mampu mengintegarsikan penerapan 8 SNP (Standar Nasional Pendidikan), PBKL (Pendidikan Berbasis Keunggulan Lokal) dan memanfaatkan Teknologi Informasi dan Komunikasi (TIK) untuk pembelajaran dan managemen sekolah. Sebuah sekolah yang diterapkan sebagai sekolah model oleh Depdiknas ini nantinya diharapkan dapat menjadi rujukan baik dari segi pembinaan, kondisi fisik, pembelajaran, manajerial, kepemimpinan dan sebagainya yang terkait dengan SNP, PBKL dan TIK bagi sekolah lain.

Sekolah model yang dikembangkan di kabupaten Gresik bermacam-macam. Ada sekolah model ke-olah raga-an, sekolah model kesenian dan kebudayaan lokal, sekolah model pengembangan lingkungan hidup atau adiwiyata, sekolah model pengembangan lesson study, dan lain-lain. MINU Trate Putri Gresik diusulkan oleh Dinas Pendidikan Kabupaten sebagai salah satu sekolah model lesson study atau LSBS. Ada beberapa sekolah yang diusulkan baik jenjang sekolah dasar maupun sekolah menengah. Setelah melalui seleksi akhirnya MINU Trate Putri Gresik lolos sebagai sekolah model lesson study (LSBS). Hal ini dibuktikan dengan Surat Keputusan Kepada Dinas Pendidikan Kabupaten Gresik sebagai kepanjangan tangan Bupati Gresik.

Sebagai sekolah yang sudah ditetapkan sebagai pilot project LSBS, MINU Trate Putri Gressik berkomitmen untuk menerapkan program-programnya yaitu: pengembangan kebijakan sekolah berbasis kolaboratif, pengembangan kurikulum berbasis LSBS, pengembangan pembelajaran berbasis lesson study, pengembangan dan atau pengelolaan sarana prasarana pendukung sekolah yang menunjang LSBS. Keberadaan sebuah lembaga sekolah tidak bisa dilepaskan dengan visi dan misi organisasinya. Visi dan misi menjadi dasar dan tujuan utama beroperasinya suatu organisasi. MINU Trate Putri Gresik memiliki visi dan misi yang proses perumusannya melalui pembicaraan antara kepala sekolah dengan guru, tata usaha, siswa dan komite sekolah. Demikian hasil dari wawancara tentang perumusan dan penetapan visi dan misi sekolah MINU Trate Putri Gresik. Dengan memperhatikan hasil wawancara dan dokumentasi yang telah dilakukan dapat disimpulkan bahwa proses perumusan visi dan misi melibatkan seluruh warga sekolah yang terdiri dari kepala sekolah, guru, tata usaha, siswa dan komite sekolah.

Kebijakan program LSBS membutuhkan sumber daya manusia yang handal dalam mewujudkan sekolah yang berbasis peningkatan mutu pembelajaran ini . Berbagai upaya telah dilakukan agar SDM di bidang LS ini memiliki pengetahuan yang lebih unggul antara lain dengan mengikuti berbagai workshop baik yang dilakukan oleh sekolah sendiri maupun dari pihak luar, mengikuti seminar antara lain seminar tentang model pembelajaran, studi banding, dan mendatangkan pakar LS dari lembaga yang kompeten seperti dari UM, Unesa maupun pengawas.

Kegiatan selama implementasi program LSBS ini membutuhkan dana, berbagai usaha sekolah telah dilakukan agar semua program terlaksana dengan baik . Dari hasil penelitian dapat disimpulkan bahwa sumber dana untuk kegiatan LSBS berasal dari dana BOS, dan juga bantuan dari seluruh warga. Pelaksanaan kurikulum berbasis Lesson Study (LSBS) meliputi pengembangan model pembelajaran berbasis kelompok kerja guru (KKG), pengembangan model pembelajaran berbasis kolaboratif (LS) dan pemanfaatan teknologi informasi (TI), penggalian dan pengembangan materi dan persoalan bersama, dan pengembangan metode belajar berbasis kerja sama. Dalam proses penyusunan kurikulum, MINU Trate Putri Gresik selalu melakukan evaluasi dan perbaikan-perbaikan. Biasanya kegiatan ini dilaksanakan di awal tahun pelajaran dalam forum bersama penyusunan Rencana 
Pendapatan dan Belanja Sekolah (RAPBS). Penyusunan program pembelajaran beserta piranti-piranti yang terkait dengannya disusun oleh Kelompok Kerja Guru (KKG).

Pengembangan dan pengelolaan sarana pendukung sekolah yang memadai sangat besar artinya dalam menunjang keberhasilan implementasi kebijakan program LSBS. Unsur penunjang yang paling pokok dalam implementasi program Lesson Study Berbasis Sekolah (LSBS) di MINU Trate Putri Gresik adalah adanya kebijakan dari pemerintah, dalam hal ini adalah Dinas Pendidikan Kabupaten Gresik. Adanya kepercayaan pemerintah terhadap MINU Trate Putri sebagai pilot project sekolah model LS membuat seluruh civitas akademika MINU Trate Putri Gresik berbangga hati sekaligus menganggapnya sebagai tantangan. Hal ini bisa dipahami karena lokasi MINU Trate Putri Gresik yang sangat dekat dengan sekolah favorit di kota selalu dibanding-bandingkan mutunya dengan sekolah di kota. Penunjukan sekolah model seolah menjadi angin segar sebagai langkah awal peningkatan mutu agar MINU Trate Putri Gresik dijadikan rujukan utama para siswa bukan sebagai second choice (pilihan kedua). Implementasi program LSBS ini memiliki dampak positif terhadap sekolah diantaranya adanya perubahan perilaku guru yang lebih terbuka dan kooperatif, pembelajaran yang lebih menyenangkan, bertambahnya sarana penunjang dan banyaknya prestasi yang diraih baik oleh sekolah, para gurunya maupun para siswanya.

Secara garis besar dampak dari program LSBS dapat diuraikan sebagai berikut: Rangkaian kegiatan LS yang sangat mengutamakan kerja tim membawa pengaruh terhadap sikap keterbukaan dalam manajemen pembelajaran. Para guru lebih membuka diri untuk saling koreksi, saling memberi masukan dan saling melengkapi kelemahan yang ada. Kerja tim juga berdampak munculnya rasa kekeluargaan yang tinggi sehingga suasana di sekolah berubah menjadi cair, guyup rukun seperti dalam keluarga. Proses kegiatan pembelajaran berbasis LS yang dipersiapkan lebih matang dalam tim dan dipraktikkan secara tim pula menimbulkan perubahan perilaku siswa. Siswa lebih terbiasa diskusi, saling menghargai pendapat teman, terbuka untuk dikritik, dan lebih berani tampil.

Pembelajaran berbasis LS dipersiapkan secara kelompok dalam tahap plan. Semua perangkat dipersiapkan bersama. Mulai dari silabus, RPP, LKS, lembar observasi, lembar penilaian, alat peraga, alat presentasi bahkan sampai teknik mengajarkannya. Dampaknya adalah sebuah pembelajaran yang menarik. Modelnya berbeda dari biasanya. Peraganya beragam. Sarananya lebih lengkap. Dan suasana pembelajaran yang kondusif. Dengan adanya LSBS, maka pihak sekolah berhasil menambah fasilitas yang asalnya kurang optimal. Di antaranya adalah LCD . Semenjak program LSBS dicanangkan sampai saat ini, sudah banyak penghargaan yang diraih. Penghargaan tersebut terkategori prestasi untuk sekolah, prestasi para guru, dan juga untuk prestasi para siswanya sebagaimana yang sudah tercatat pada bagian sebelumnya.

\section{Kesimpulan}

Kesimpulan yang diperoleh dari temuan penelitian ini adalah Implementasi kebijakan program baik ditinjau dari pengembangan kebijakan sekolah model LSBS, pengembangan kurikulum berbasis Lesson Study, pengembangan pembelajaran berbasis lesson study, dan pengembangan dan atau pengelolaan sarana prasarana pendukung sekolah yang menunjang LSBS sudah berjalan dengan baik. Hal-hal yang menunjang dalam pengimplementasian kebijakan program Lesson Study Berbasis Sekolah (LSBS) adalah adanya kebijakan bupati melalui Kepala Dinas Pendidikan kabupaten Gresik, Sumber Daya Manusia (SDM) yang sudah memadai, Komitmen dan kekompakan seluruh civitas akademika untuk mendukung program, sarana dan prasarana yang ada, dan adanya anggaran yang memadai. Sedangkan 
hal-hal yang menjadi kendala dalam pengimplementasian kebijakan Program Lesson Study Berbasis Sekolah (LSBS) adalah belum lengkapnya fasilitas penunjang seperti LCD dan sound system di semua kelas, alat perekam kegiatan, model bangku yang panjang, jaringan internet yang lemah serta belum tersosialisasikannya visi misi sekolah dengan baik, padatnya acara sekolah, padatnya jam mengajar bagi guru dan rasa takut siswa.

Solusi yang diterapkan dalam mengatasi kendala pengimplementasian kebijakan Program Lesson Study Berbasis Sekolah (LSBS) adalah pemenuhan fasilitas penunjang dengan menjalin kerja sama dengan pihak luar, pengadaan pelatihan atau workshop bagi guru dengan mendatangkan ahlinya, peningkatan sarana sosialisasi visi misi sekolah lewat spanduk dan edaran atau plakat, pengaturan ulang jadwal kegiatan dan jadwal pelajaran, serta pemberian motivasi bagi siswa. Dampak implementasi kebijakan Program Lesson Study Berbasis Sekolah (LSBS) di MINU Trate Putri Gresik adalah perubahan perilaku guru yang lebih terbuka, kooperatif, dan korektif, pembelajaran yang lebih menyenangkan, bertambahnya sarana penunjang dan banyaknya prestasi yang diraih baik oleh sekolah, para gurunya maupun para siswanya.

\section{Saran}

Saran yang dapat disampaikan berdasarkan hasil penelitian ini antara lain adalah; (1) Bagi sekolah hendaknya lebih meningkatkan fasilitas penunjang baik yang bersifat material maupun kabijakan serta lebih memberi kesempatan kepada warganya untuk mengembangkan potensinya. (2) Bagi para guru hendaknya selalu mengembangkan sikap membuka diri untuk peningkatan profesionalisme, mengandalkan teamwork dalam bekerja, dan berusaha menambah terus wawasan dan keterampilan di bidang pembelajaran. (3) Bagi Dinas Pendidikan hendaknya memperbanyak sekolah model atau pilot project school terutama sekolah model LSBS dan menunjangnya dengan berbagai fasilitas yang dibutuhkan.

\section{Daftar Pustaka}

Joharmawan, Ridwan. (2005). Reformasi Sekolah Melalui kegiatan Lesson Study, makalah disampaikan dalam seminar dan workshop Lesson Study di FMIPA UM, 21 Juni 2005

Karim, Muchtar A. (2005). Lesson Study: Cara Implementasinya, makalah disampaikan dalam seminar dan workshop Lesson Study di FMIPA UM, 21 Juni 2005

Inerson, P.W., and Yoshida, M. (2005). Building Our Understanding of Lesson Study.Philadelphia, PA: Researchfor Better Schools.

Lewis, Catherine C. (2002). Lesson study: A Handbook of teacher-Led Instructional Change. Philadelphia. PA: Research for Better schools,Inc.

Moleong, Lexy. (2014). Metode Penelitian Kualitatif , Edisi Revisi. PT Remaja Rosdakarya, Bandung.

Rahayu, Sri. (2005). Lesson Study sebagai model pengembangan Profesi Guru dalam upaya meningkatkan pembelajaran MIPA, makalah disampaikan dalam seminar dan workhop Lesson Study di FMIPA UM, 21 Juni 2005

Susilo, Herawati. (2005). Lesson Study: Apa dan Mengapa. makalah disampaikan dalam seminar dan workshop Lesson Study di FMIPA UM, 21 Juni 2005

Susilo, Herawati dkk. (2009). Lesson Study Berbasis Sekolah, Guru Konservatif Menuju Guru Inovatif, Bayumedia Publishing. Malang.

Peraturan Pemerintah Republik Indonesia Nomor 19 Tahun 2005 Tentang Standar Nasional Pendidikan 